\title{
Model test investigation on an innovative lifting system for deepwater riser installation
}

\author{
Mao Dongfeng ${ }^{1,2}$, Duan Menglan², Wang $\mathrm{Yi}^{3}$, He Ning ${ }^{4}$, Chen Bangmin ${ }^{2}$ and \\ Zhang Yingjie ${ }^{2}$ \\ ${ }^{1}$ School of Mechanical Engineering, Yangtze University, Jinzhou Hubei 434023, China \\ ${ }^{2}$ Offshore Oil/Gas Research Center, China University of Petroleum, Beijing 102249, China \\ ${ }^{3}$ Department of Naval Architecture \& Ocean Engineering, Dalian University of Technology, Dalian, Liaoning 116023, China \\ ${ }^{4}$ Offshore Oil Engineering Co., Ltd., Tanggu, Tianjin 300452, China
}

(C) China University of Petroleum (Beijing) and Springer-Verlag Berlin Heidelberg 2010

\begin{abstract}
An S-lay crane barge, named CNOOC 201, has been built for pipe laying in deepwater oil/ gas fields in the South China Sea. It is due to be commissioned by the end of the year 2010. A special lifting system is developed to meet the challenge that installing deepwater risers from an S-lay barge is difficult and has not been achieved. The purpose of this paper was to investigate the model test on such an innovative system, which has to be done before field application. By applying the similarity theory, the movement of the S-lay barge is simulated through a six degrees-of-freedom motion platform, and a truncated model riser is utilized for the model testing. The displacement and force boundary conditions at the truncated position of the riser are obtained from the catenary governing equation and become realized by a slideway cart and a loading system designed to control the configuration of the model riser, which presents a similar configuration to a real riser in deepwater. The test results are in very good agreement with theoretical calculations, showing that the active truncated test is applicable for controlling the configuration of the deepwater riser in model testing investigation.
\end{abstract}

Key words: Deepwater riser, lifting system, model test, six degrees-of-freedom, motion platform, active truncation

\section{Introduction}

The field LW3-1 is the first giant gas field to be discovered in deep water in China. An S-lay crane barge, named CNOOC 201 , has been built for pipe laying in deepwater $(3,000 \mathrm{~m})$ in South China Sea and will be in operation in the end of the year 2010 (Zhen, 2008). It will play a very important role in the development of the gas field LW3-1. Compared with horizontal operations of pipe laying in an S-lay barge, vertical operations in a J-lay barge are much more practical for deepwater riser installation. In addition, it is difficult to transmit the tension from an S-lay barge to a production platform in riser installation because of the big stinger system at the barge rear (Bouwman, 2007). A J-lay tower was taken into consideration in conceptual design of the CNOOC 201, but not accepted in detailed design. The J-lay tower design makes much easier to perform the installation of deepwater risers, while the S-lay design has never been used for such an operation. It has been well recognized that a multi-functional barge is required to fulfill all operations in the development of

*Corresponding author. email address: mlduan@cup.edu.cn Received March 31, 2010 offshore oil fields including pipeline/riser laying, installation of various kinds of subsea production hardware in order to save time in offshore operations, and to reduce operational and capital expenses (OPEX and CAPEX). In such a case, a special lifting system for deepwater riser installation for the CNOOC 201 was designed in reference to the technology of a J-lay system (Jiang et al, 2009; Duan et al, 2010). The overall dimension of the lifting system is $5.6 \mathrm{~m} \times 4.2 \mathrm{~m} \times 13.5 \mathrm{~m}$ with a lifting capacity of up to 400 tonnes. The system is to be positioned on the port side of the vessel and connected with the deck girder of the barge, as shown in Fig. 1. The success of such an innovative design not only satisfies the installation of risers but also meets the requirement of the subsea hardware such as pipeline end termination (PLET), pipeline end manifold (PLEM), subsea manifolds, jumpers and spools (Duan, 2010).

The special lifting system for deep water riser installation is large and complex, withstanding loads not only from lifting operation of the riser but also from dynamics of the barge besides environmental loads from waves, currents and wind. The theoretical and numerical calculations for the design of the system are not sufficient for its development, and model testing has to be conducted to verify the performance both in 

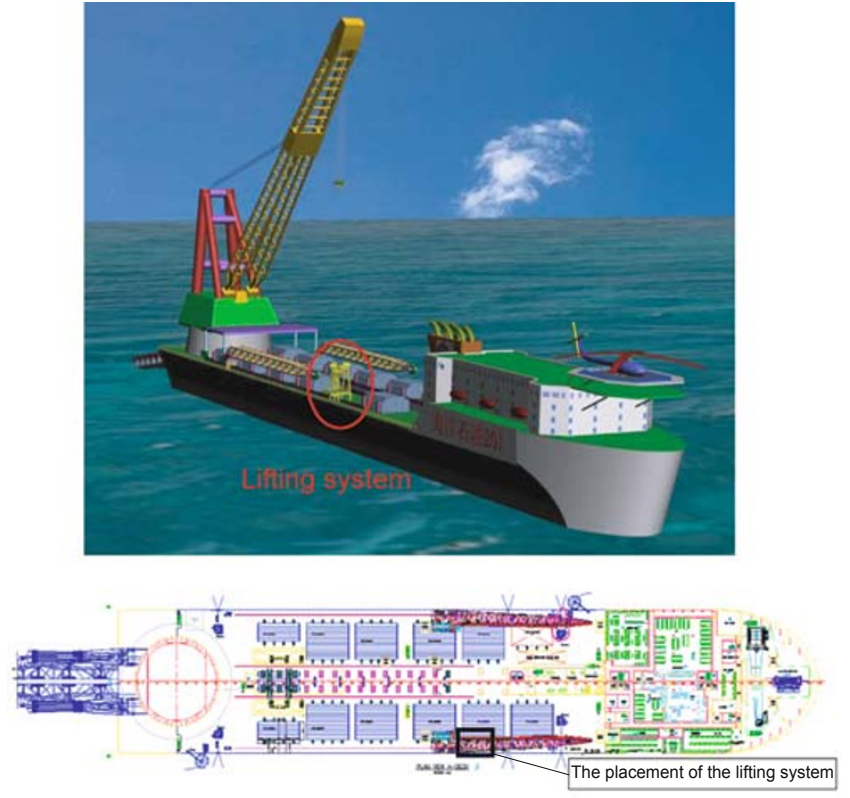

Fig. 1 The placement of the lifting system on the target vessel -CNOOC 201

functional operations and in reliability of the whole system. It is also important to get more information and experience on how to operate such creative equipment for in-situ application. In this way, the similarity theory is applied to simulate the movement of the S-lay barge by using a six degrees-offreedom (6-DOF) motion platform, and an active truncation test method is developed to model the deepwater riser where the catenary governing equation is used for definition of the displacement and force boundary conditions at the truncated position of the riser. To control the configuration of the model riser, a slideway cart and a loading system were designed. The results show that the active truncation test method is applicable for controlling the configuration of the deepwater riser in model testing investigation.

\section{Model testing design}

To make the model size large enough to meet test requirements, a larger reduced scale of 1:10 is taken for a water depth of $3,000 \mathrm{~m}$. The following parts are detailed representation for the similarity deduction, simulation of riser and boundary conditions at the truncated position, simulation of the vessel motion and of riser lifting, and scheme of model test.

\subsection{The similarity deduction for the deepwater riser lifting system}

The model testing of the riser lifting system is mainly concerned with the force due to gravity on the riser and the stresses in the lifting system. Therefore, two $\pi$ numbers are chosen in the test: one is the Froude number and the other the ratio of elastic force over inertia force (Л.И.СеДОВ, 1982; Yang et al, 2008).

Gravity: $F_{g}=\rho g l^{3}$.

Inertia force: $F_{i}=r l^{2} v^{2}$.

Elastic force: $F_{s}=A \sigma$.

Froude number is defined as:
$F_{r}=\sqrt{\frac{F_{i}}{F_{g}}}=\sqrt{\frac{\rho l^{2} v^{2}}{\rho g l^{3}}}=\frac{v}{\sqrt{g l}}$

Froude number for original prototype:

$F_{r}=\frac{v}{\sqrt{g l}}$

Froude number for the model:

$$
F_{r}^{*}=\frac{v^{\prime}}{\sqrt{g^{\prime} l^{\prime}}}
$$

Froude numbers for original prototype and the model should be the same, i.e.,

$$
F_{r}=F_{r}^{*}
$$

Moreover, the force due to gravity is constant, i.e., $g=g^{\prime}$. Substituting this and Eqs. (2)-(3) into Eq. (4) yields,

$$
\frac{v}{v^{\prime}}=\sqrt{\frac{l}{l^{\prime}}}
$$

The ratio of elastic force to inertia force gives,

$$
\frac{F_{s}}{F_{i}}=\frac{A \sigma}{\rho l^{2} v^{2}}=\frac{F_{s}^{*}}{F_{i}^{*}}=\frac{A^{\prime} \sigma^{\prime}}{\rho^{\prime} l^{\prime 2} v^{\prime 2}}
$$

Thus, the ratio of the stresses in the model to those of the initial prototype is,

$$
\frac{\sigma^{\prime}}{\sigma}=\frac{l^{\prime}}{l}
$$

From the similarity criterion of gravity and inertia force, the reduced scale similarity constants of time, velocity and force can be derived. If the length similarity constant between the model system and the prototype system is $1: 10$, the other relative reduced scale similarity constants in the test are shown in Table 1.

Table 1 Reduced scale similarity constants

\begin{tabular}{ccccccc}
\hline Parameter & Size & Time & Velocity & Force & Mass & Stress \\
\hline Similarity constants & 0.1 & 0.32 & 0.32 & 0.001 & 0.001 & 0.1 \\
\hline
\end{tabular}

\subsection{Simulation of deepwater riser by the active truncated test}

As well known, if the riser is modeled strictly in accordance with a reduced scale of 1:10, the modeled length of a $3,000 \mathrm{~m}$ riser is still $300 \mathrm{~m}$ while the outer diameter of $16^{\prime \prime}(406.4 \mathrm{~mm})$ and the wall thickness of $2.32 \mathrm{~mm}$ will be only $1.6^{\prime \prime}(40.64 \mathrm{~mm})$ and $0.232 \mathrm{~mm}$, respectively. This means, it is impossible to manufacture the model riser with so small a diameter, and is not feasible to test so long a riser in the laboratory (Zhang et al, 2009). Based on the hybrid model test method (Watts, 1999; 2000; Chen et al, 2000), a truncated model riser is taken for experimental simulation, i.e., the riser is cut off at a suitable height and the truncated riser is still scaled down with initial reduced scale. Although the model riser is truncated, it shall take exactly the same configuration of the real catenary riser. 
As presented in Fig. 2, the riser is supposed to be cut off $30 \mathrm{~m}$ below the water surface. The truncated riser is scaled down strictly in a reduced scale 1:10, giving the values of the outer diameter, thickness and the length of the truncated model riser for a $16^{\prime \prime}$ riser respectively as $4.064 \mathrm{~mm}, 0.232$ $\mathrm{mm}$, and $3 \mathrm{~m}$. The boundary conditions at the truncated position of the model riser can be obtained from the catenary formula as follows.

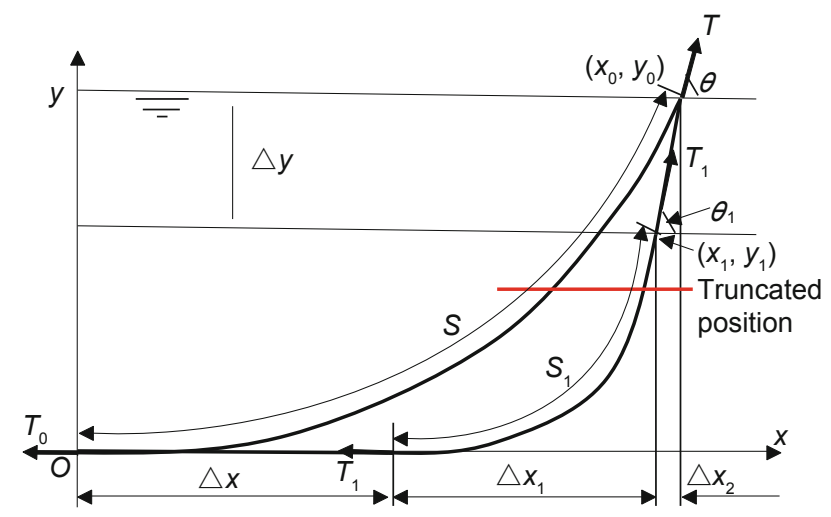

Fig. 2 Configuration of the catenary riser

The initial configuration of the riser is determined by the governing equation for the catenary (Pytel and Kiusalaas, 1994):

$$
\begin{aligned}
& S=\sqrt{y^{2}+2 \frac{T_{0}}{\omega_{0}} y} \\
& x=\frac{T_{0}}{\omega_{0}} \ln \left[\left(\frac{\omega_{0}}{T_{0}} y+1\right)+\sqrt{\left(\frac{\omega_{0}}{T_{0}} y+1\right)^{2}-1}\right] \\
& T=\frac{y \omega_{0}}{1-\cos \theta} \\
& T_{0}=\frac{y \omega_{0} \cos \theta}{1-\cos \theta}
\end{aligned}
$$

where $T$ is the axial tensile force, $\mathrm{kgf} ; \theta$ is the dip angle of the riser, degrees; $T_{0}$ is the horizontal component force, $\operatorname{kgf} ; S$ the length of the riser, $\mathrm{m}$; and $\omega_{0}$ are the unit length weight of the riser, $\mathrm{kgf} / \mathrm{m}$.

Assuming that the riser is lowered from state $S$ to $S_{1}$, with a lowering depth of $\Delta y$, and keeping the length of the riser unchanged after lowering, i.e., $x_{0}=\Delta x+\Delta x_{1}+\Delta x_{2}$ and $S=\Delta x+S_{1}$, the catenary governing equation will yield a relation between the lowering depth and the top end dip angle of the riser after lowering as follows:

$$
\begin{aligned}
& x_{0}=\frac{\Delta y}{\tan \theta_{1}}+\sqrt{y_{0}^{2}+2 \frac{y_{0} \omega_{0} \cos \theta}{\omega_{0}(1-\cos \theta)} y_{0}} \\
& -\sqrt{y_{1}^{2}+2 \frac{y_{1} \omega_{0} \cos \theta_{1}}{\omega_{0}\left(1-\cos \theta_{1}\right)} y_{1}}+\frac{y_{1} \omega_{0} \cos \theta_{1}}{\omega_{0}\left(1-\cos \theta_{1}\right)} \times \\
& \ln \left[\frac{\omega_{0}\left(1-\cos \theta_{1}\right)}{y_{1} \omega_{0} \cos \theta_{1}} y_{1}+1+\sqrt{\left(\frac{\omega_{0}\left(1-\cos \theta_{1}\right)}{y_{1} \omega_{0} \cos \theta_{1}} y_{1}+1\right)^{2}-1}\right]
\end{aligned}
$$

Eq. (12) shows that the dip angle of the riser top end in the new configuration can be determined from the lowering depth, and the coordinates $(x, y)$, tip angle and axial tension force at an arbitrary position, can be obtained.

Let the tip angle of a $16^{\prime \prime}$ riser at a water depth of 3,000 m be $80^{\circ}$, the riser be truncated at the position under water $30 \mathrm{~m}$, and lowering depth be $0-30 \mathrm{~m}$, the lowering depth, horizontal coordinate $x$, axial tension and tip angle at the truncated position where $y=2970 \mathrm{~m}$ can be solved from Eqs. (8)-(12). In this way, the boundary conditions of the model riser are obtained as shown in Table 2.

Table 2 Calculated boundary conditions of model riser

\begin{tabular}{cccc}
\hline $\begin{array}{c}\text { Lowering depth } \\
h, \mathrm{~m}\end{array}$ & $\begin{array}{c}x \text {-coordinate } \\
\mathrm{m}\end{array}$ & $\begin{array}{c}\text { Axial tension } \\
T, \mathrm{kgf}\end{array}$ & $\begin{array}{c}\text { Tip angle at the } \\
\text { truncated position } \\
\text { Degrees }\end{array}$ \\
\hline 0 & 153.053 & 216.025 & 79.916 \\
5 & 153.058 & 215.616 & 80.007 \\
10 & 153.063 & 215.219 & 80.096 \\
15 & 153.067 & 214.823 & 80.184 \\
20 & 153.071 & 214.456 & 80.267 \\
25 & 153.075 & 214.064 & 80.355 \\
30 & 153.080 & 213.675 & 80.443 \\
\hline
\end{tabular}

\subsection{Simulation of the vessel motion}

Fig. 3 shows the motion of a vessel in 6-DOF: three translations (surge, sway, heave) and three rotations (roll, pitch, yaw). A simulator was developed for the 6-DOF motion of any vessel (Zhang and Liu, 2009; Yang et al, 2003; Furutani et al, 2004; Greenberg et al, 2004), and all data for the motion simulation of the CNOOC 201 barge were obtained as presented in Table 3 from hydrodynamic analysis of the S-lay barge in conditions of South China Sea (Gusto, 2006): wind velocity of $16 \mathrm{~m} / \mathrm{s}$, wave height $H_{\mathrm{S}}$ of $3 \mathrm{~m}$, wave period $T$ of 6-9 s, current velocity of $3 \mathrm{kn}$, wave spectrum of Jonswap, and wave-to-course angle $\varphi$ of $0^{\circ}-360^{\circ}$.

Assuming that the phase differences between different motions are all $90^{\circ}$, all the parameters for the model testing can be obtained from Table 3 and are presented for all the 24 operating conditions in Table 4.

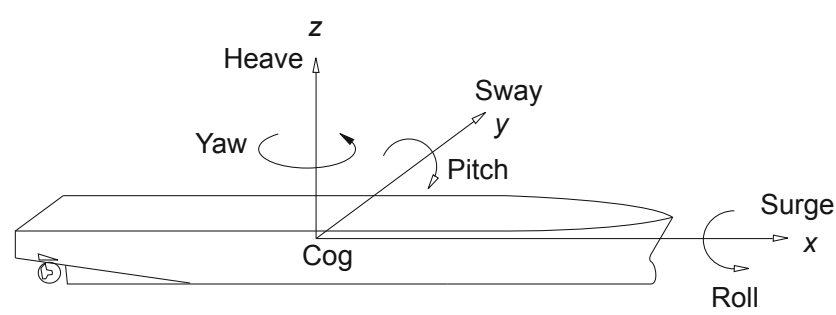

Fig. 3 The 6-DOF motion of the vessel 
Table 3 Barge motion references

\begin{tabular}{ccccccc}
\hline $\begin{array}{c}\text { Condition } \\
\text { No. }\end{array}$ & $\begin{array}{c}\text { Wave } \\
\text { height } \\
H_{\mathrm{S}}, \mathrm{m}\end{array}$ & $\begin{array}{c}\text { Heading } \\
\text { Degrees }\end{array}$ & $\begin{array}{c}\text { Wave } \\
\text { period } \\
T, \mathrm{~s}\end{array}$ & $\begin{array}{c}\text { Heave } \\
\text { amplitude } \\
\mathrm{m}\end{array}$ & $\begin{array}{c}\text { Roll } \\
\text { Degrees }\end{array}$ & $\begin{array}{c}\text { Pitch } \\
\text { Degrees }\end{array}$ \\
\hline 1 & 3 & 0 & 9 & 0.46 & 0 & 0.75 \\
2 & 3 & 45 & 9 & 0.47 & 0.93 & 1.14 \\
3 & 3 & 90 & 9 & 1.69 & 2.07 & 0 \\
4 & 3 & 0 & 9 & 0.40 & 0 & 0.77 \\
5 & 3 & 45 & 9 & 0.47 & 1.10 & 1.27 \\
6 & 3 & 90 & 9 & 2.38 & 2.73 & 0 \\
\hline
\end{tabular}

\subsection{Simulation of the riser lifting system}

The overall dimension of the model lifting system shown in Fig. 4 is $0.56 \mathrm{~m} \times 0.42 \mathrm{~m} \times 1.1 \mathrm{~m}$ in $1: 10$ scale.

During lifting operation, the tensile force in the Abandonment \& Recovery (A\&R) cable may vary in a small range because of the barge motion. It is necessary to measure the tensile force to determine the variation range of the A\&R cable in the absence of a constant tensioning system. The measurement was performed by using S-shape tension sensors equipped with an XSB5 digital monitor, as shown in Fig. 5.

The riser will be held by its fixture as soon as it is lifted from subsea to the system. The barge movement has

Table 4 Test operational conditions

\begin{tabular}{|c|c|c|c|c|c|c|c|c|c|}
\hline \multirow[b]{2}{*}{$\begin{array}{c}\text { Condition } \\
\text { No. }\end{array}$} & \multirow[b]{2}{*}{$\begin{array}{c}\text { Wave height } \\
H_{\mathrm{S}}, \mathrm{m}\end{array}$} & \multirow[b]{2}{*}{$\begin{array}{l}\text { Heading } \\
\text { Degrees }\end{array}$} & \multirow[b]{2}{*}{$\begin{array}{c}\text { Wave period } \\
T, \mathrm{~s}\end{array}$} & \multicolumn{2}{|c|}{ Heave } & \multicolumn{2}{|c|}{ Roll } & \multicolumn{2}{|c|}{ Pitch } \\
\hline & & & & $\underset{\mathrm{m}}{\text { Amplitude }}$ & $\begin{array}{c}\text { Phase } \\
\text { Degrees }\end{array}$ & $\begin{array}{l}\text { Amplitude } \\
\mathrm{m}\end{array}$ & $\begin{array}{l}\text { Phase } \\
\text { Degrees }\end{array}$ & $\underset{\mathrm{m}}{\text { Amplitude }}$ & $\begin{array}{l}\text { Phase } \\
\text { Degrees }\end{array}$ \\
\hline 1 & 3 & 0 & 2.84 & 0.046 & 0 & 0 & 0 & 0.75 & 0 \\
\hline 2 & 3 & 0 & 2.84 & 0.046 & 90 & 0 & 0 & 0.75 & 0 \\
\hline 3 & 3 & 0 & 2.84 & 0.046 & 0 & 0 & 90 & 0.75 & 0 \\
\hline 4 & 3 & 0 & 2.84 & 0.046 & 0 & 0 & 0 & 0.75 & 90 \\
\hline 5 & 3 & 45 & 2.84 & 0.047 & 0 & 0.93 & 0 & 1.14 & 0 \\
\hline 6 & 3 & 45 & 2.84 & 0.047 & 90 & 0.93 & 0 & 1.14 & 0 \\
\hline 7 & 3 & 45 & 2.84 & 0.047 & 0 & 0.93 & 90 & 1.14 & 0 \\
\hline 8 & 3 & 45 & 2.84 & 0.047 & 0 & 0.93 & 0 & 1.14 & 90 \\
\hline 9 & 3 & 90 & 2.84 & 0.169 & 0 & 2.07 & 0 & 0 & 0 \\
\hline 10 & 3 & 90 & 2.84 & 0.169 & 90 & 2.07 & 0 & 0 & 0 \\
\hline 11 & 3 & 90 & 2.84 & 0.169 & 0 & 2.07 & 90 & 0 & 0 \\
\hline 12 & 3 & 90 & 2.84 & 0.169 & 0 & 2.07 & 0 & 0 & 90 \\
\hline 13 & 3 & 180 & 2.84 & 0.040 & 0 & 0 & 0 & 0.77 & 0 \\
\hline 14 & 3 & 180 & 2.84 & 0.040 & 90 & 0 & 0 & 0.77 & 0 \\
\hline 15 & 3 & 180 & 2.84 & 0.040 & 0 & 0 & 90 & 0.77 & 0 \\
\hline 16 & 3 & 180 & 2.84 & 0.040 & 0 & 0 & 0 & 0.77 & 90 \\
\hline 17 & 3 & 225 & 2.84 & 0.047 & 0 & 1.10 & 0 & 1.27 & 0 \\
\hline 18 & 3 & 225 & 2.84 & 0.047 & 90 & 1.10 & 0 & 1.27 & 0 \\
\hline 19 & 3 & 225 & 2.84 & 0.047 & 0 & 1.10 & 90 & 1.27 & 0 \\
\hline 20 & 3 & 225 & 2.84 & 0.047 & 0 & 1.10 & 0 & 1.27 & 90 \\
\hline 21 & 3 & 270 & 2.84 & 0.238 & 0 & 2.73 & 0 & 0 & 0 \\
\hline 22 & 3 & 270 & 2.84 & 0.238 & 90 & 2.73 & 0 & 0 & 0 \\
\hline 23 & 3 & 270 & 2.84 & 0.238 & 0 & 2.73 & 90 & 0 & 0 \\
\hline 24 & 3 & 270 & 2.84 & 0.238 & 0 & 2.73 & 0 & 0 & 90 \\
\hline
\end{tabular}




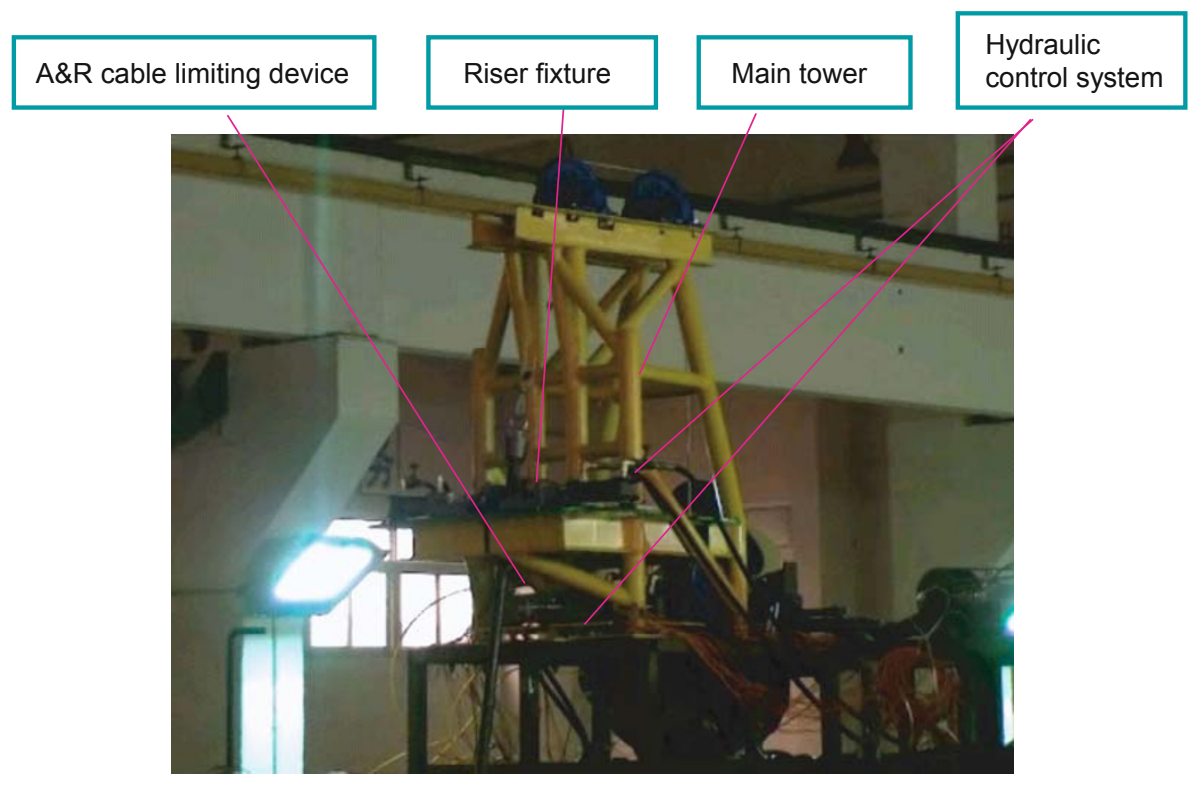

Fig. 4 Riser lifting system for model testing
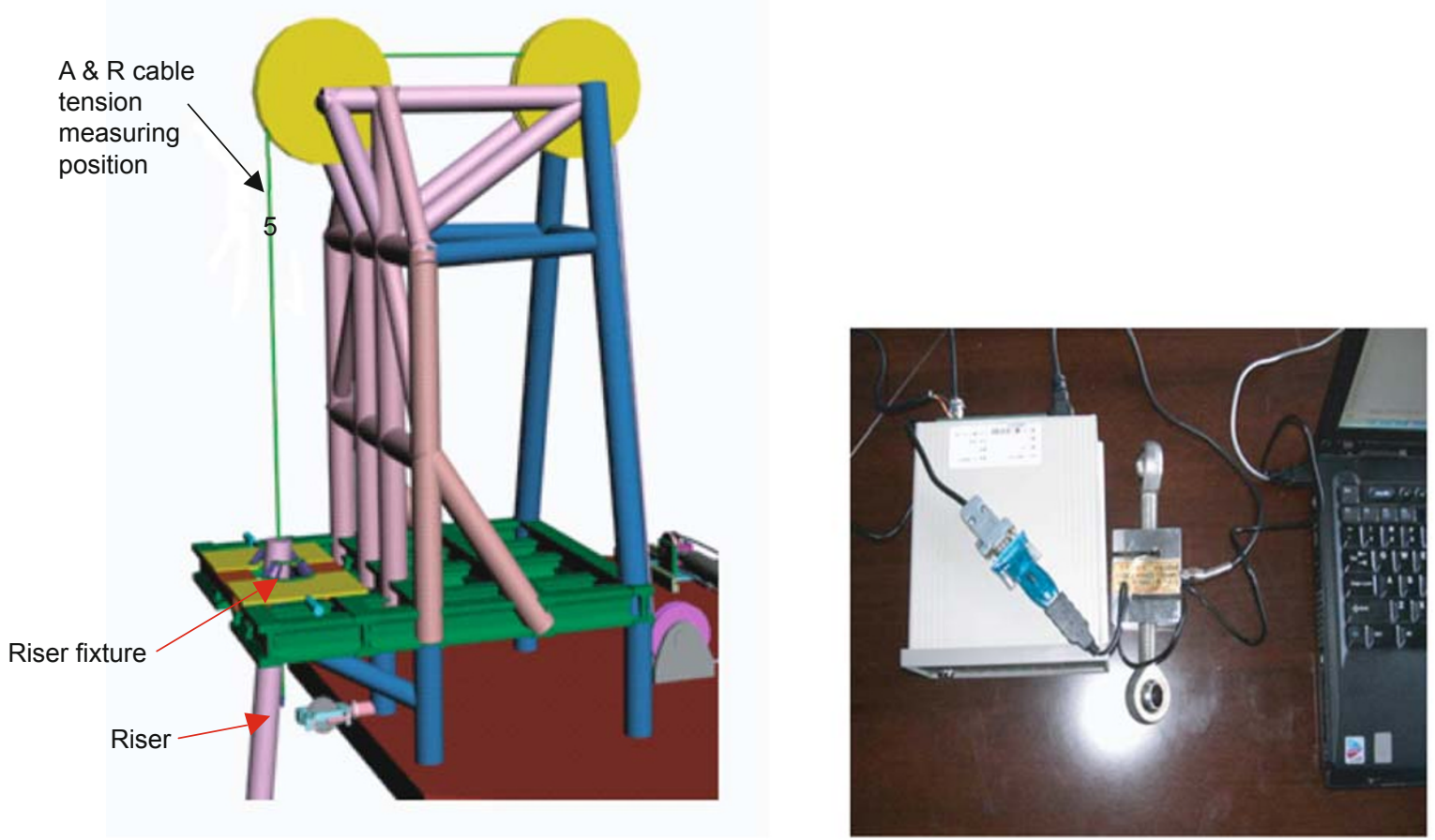

Fig. 5 A\&R cable tension measuring position and S-shape tension sensor

significant action on the riser especially when the riser has a dip angle, which will increase the stress state of the riser fixture requiring more strain gauges to monitor the stress distribution of the fixture. Fig. 6 shows 5 strain gauge positions on the riser fixture.

\subsection{Overall design of the model test system}

The model test system is schematically presented in Fig. 7. The model of the special lifting system for deepwater riser installation was set on the vessel simulator, a 6-DOF motion platform. One end of A\&R cable was connected to the model riser and the other was reeled over large pulleys to be linked to the model A\&R winch. The functional testing such as riser lifting and lowering, tension converting and hanging up to the platform, etc., was carried out, while forces and stress were recorded during the whole testing to verify the performance of the developed innovative lifting system. During the test, the configuration of the truncated model riser was strictly controlled all the way to the end of testing. Recovering of the axial force at the bottom of the riser was achieved by a balance weight hanging by a steel cable, and the truncated position was always kept by the electric cart on slideway. 


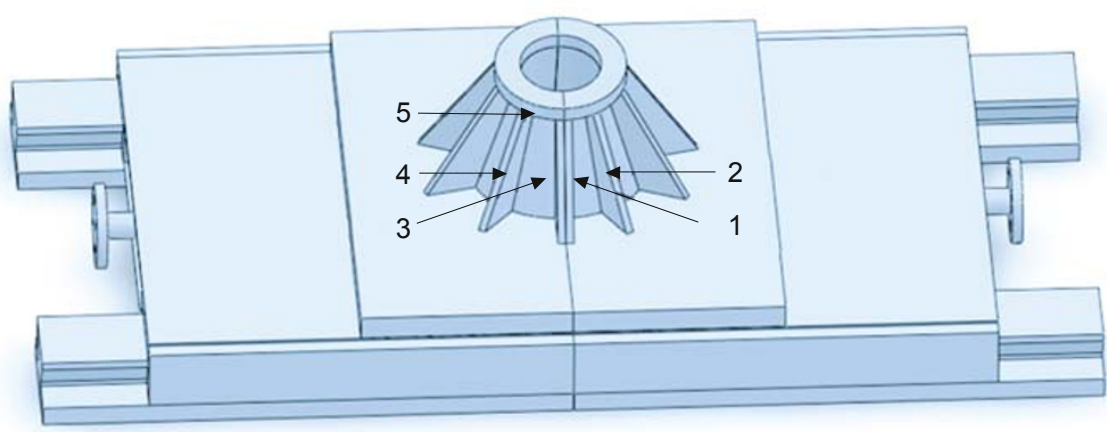

Fig. 6 Sketch of strain gauge positions on the riser fixture

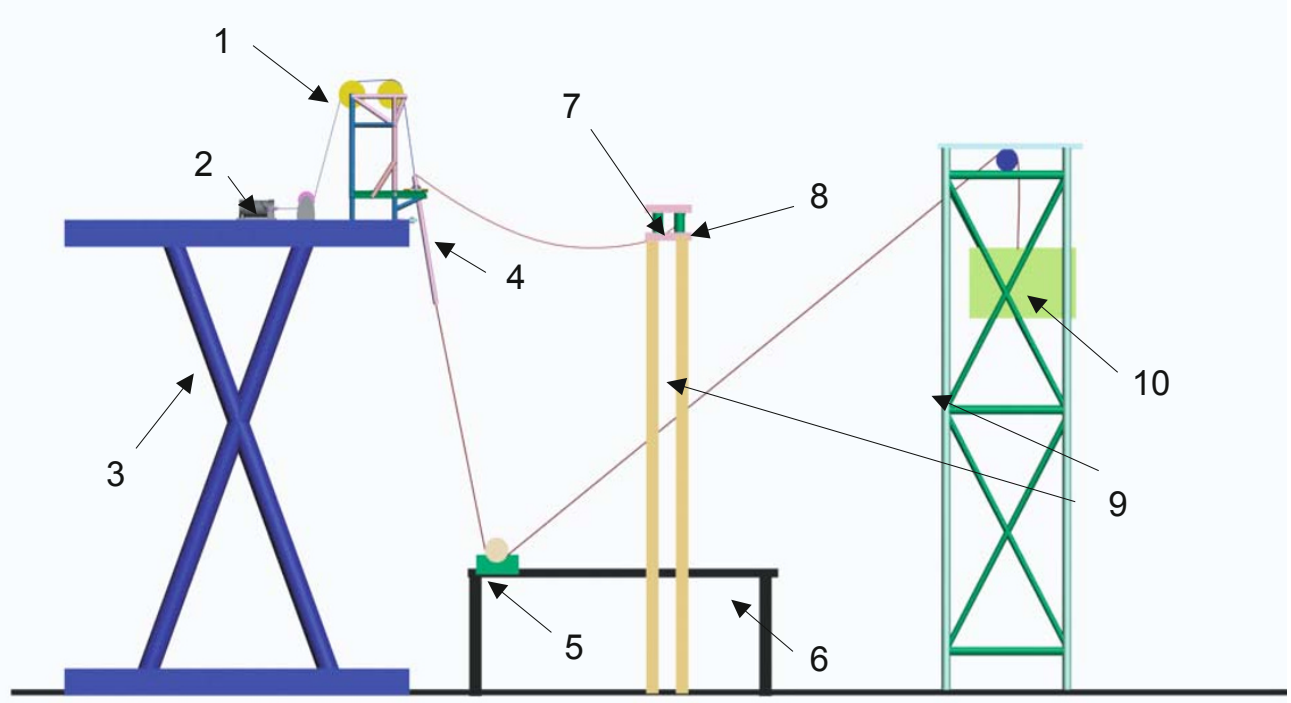

Fig. 7 Schematic presentation of the model test system

1. Model, 2. A\&R winch, 3. Vessel simulator, 4. Model riser, 5. Electric cart, 6. Slideway, 7. Target platform, 8. Platform A\&R winch, 9. Support tower, 10. Balance weight

\section{Test results and discussion}

During the test, the model riser was lifted, placed on the riser fixture and installed to the model platform successfully, and the riser and A\&R cable did not touch the model lifting system at all. All these operations showed that the A\&R cable limiting device was in effect, tension transition was successful and all functions of designed riser lifting system for deepwater riser installation were achieved.

The results on tensions in the A\&R cable and stresses in the riser fixture under 24 operating conditions are listed in Table 4. The tensions in the A\&R cable are shown in Fig. 7.

Fig. 8 shows that the tension in the A\&R cable was mainly controlled by the heave motion of the barge, and, the larger the heave amplitude, the bigger the variation range of the tension. Therefore, the stress variation range can be used to determine the lifting capacity of the A\&R winch and to check if the heave compensation could meet the requirements of all the operations. From Fig. 8, it can be seen that the maximum tension variation in the $A \& R$ cable reached $160 \mathrm{kgf}$, and the

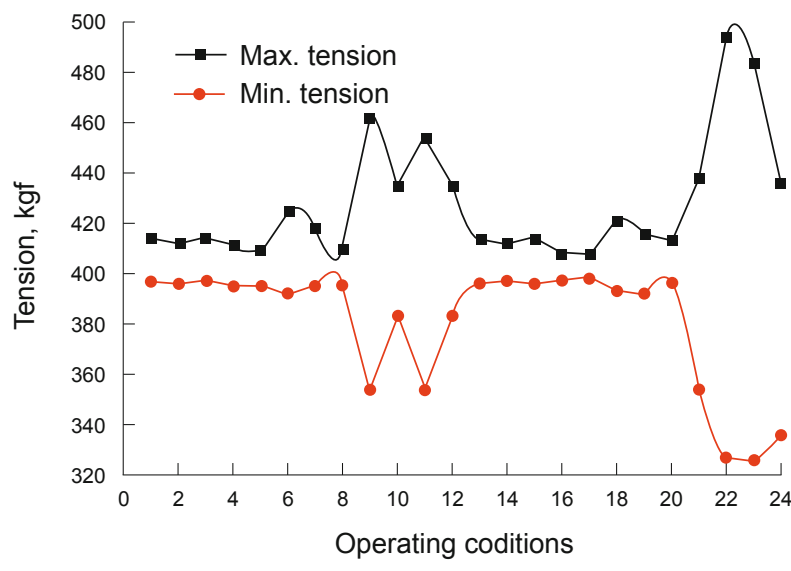

Fig. 8 Tension in the A\&R cable in different operating conditions

total weight of the riser to be lifted is recommended to be less than 320 tonnes. The ultimate bearing capacity of 400 tonnes of the $A \& R$ winch is enough for lifting risers of 16 inches in $3,000 \mathrm{~m}$ deep water. 
The finite element numerical simulation under operating condition 24, which is one of the most severe conditions, was conducted, and the results for the riser fixture are shown in Table 5 and Fig. 9. The scaled down load was adopted in the simulation.

Table 5 Numerical simulation results of the riser fixture at measuring positions

\begin{tabular}{crrrrr}
\hline Measuring position & 1 & 2 & 3 & 4 & 5 \\
Stress, $\mathrm{MPa}$ & 10.0 & 4.9 & 10.0 & 4.9 & 6.8 \\
\hline
\end{tabular}

The recorded peak stresses at 5 positions obtained from the tests under different operating conditions are shown in Figs. 10-12.

It can be seen that most of the stress peaks at different positions of the riser fixture are smaller than calculated values except under several severe operating conditions. Many factors may affect the test results, for example, adhesive effect of the strain gauges to the surface of the fixture or signal noise caused by electrical interference in the test field. However, the difference between the measured and calculated values is not large and the largest deviation does not exceed $25 \%$ of the calculated value. It is also proved that the input boundary conditions at the truncated position of the riser properly fit the initial configuration of the riser.

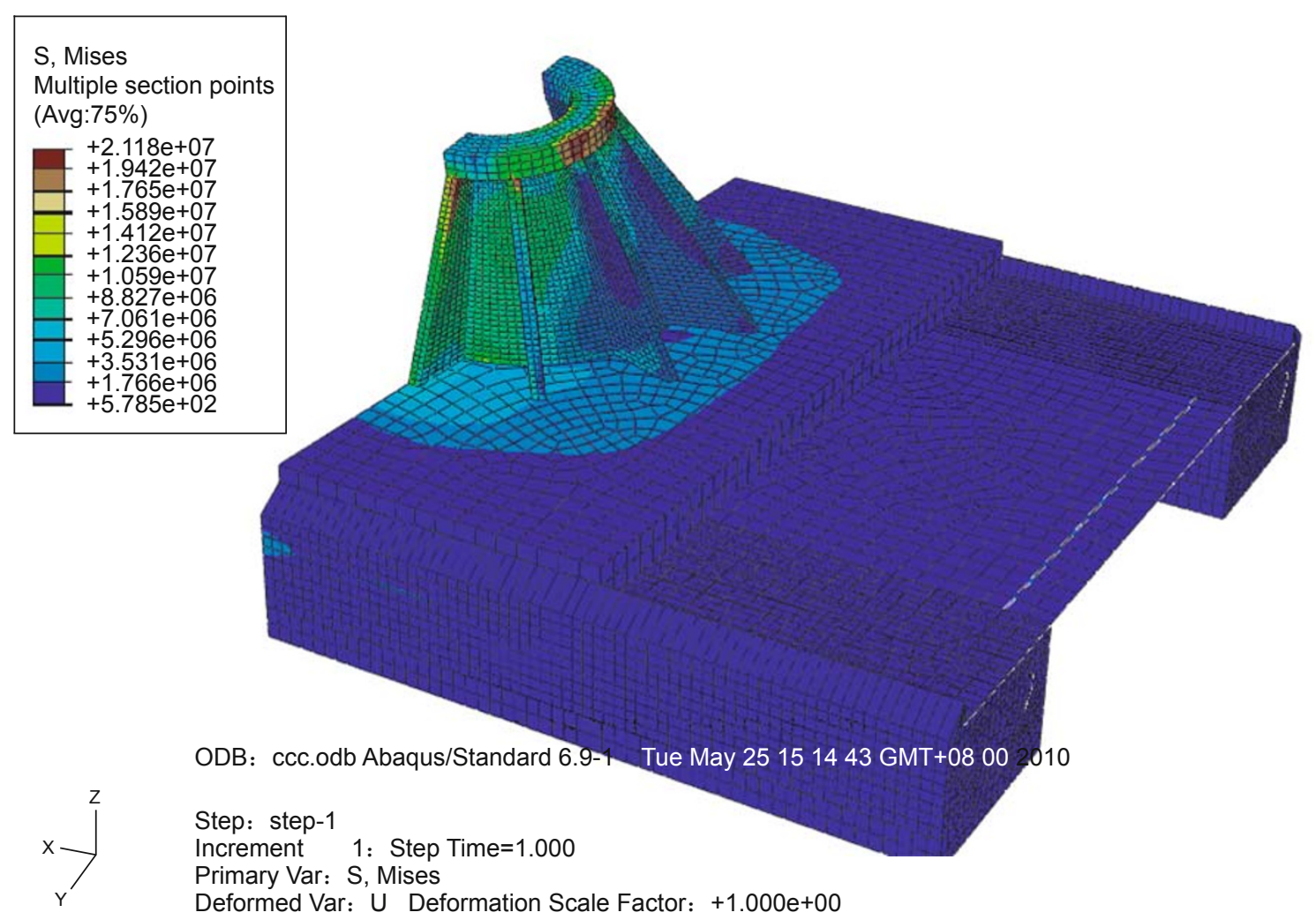

Fig. 9 Stress cloud chart of the riser fixture

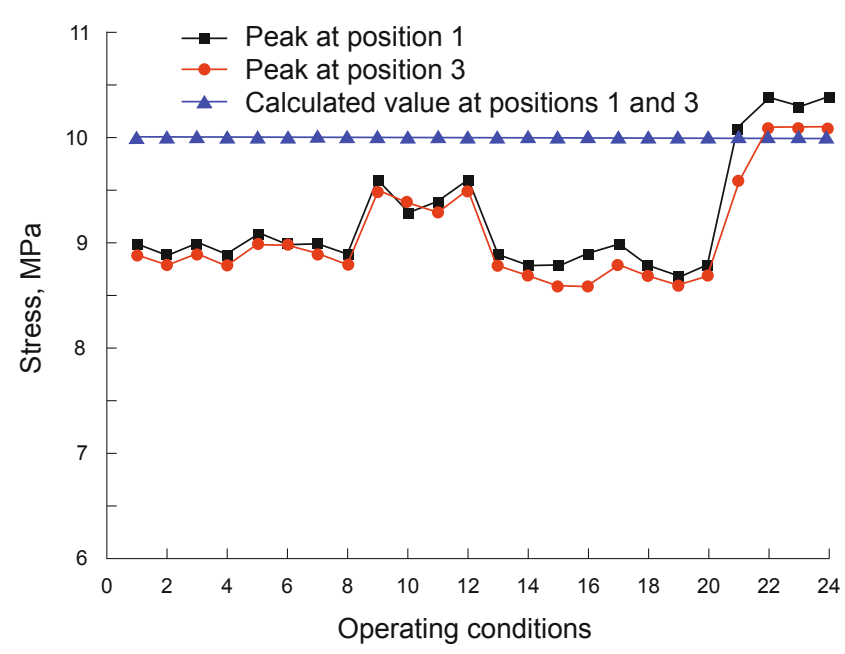

Fig.10 Measured and calculated values at positions 1 and 3

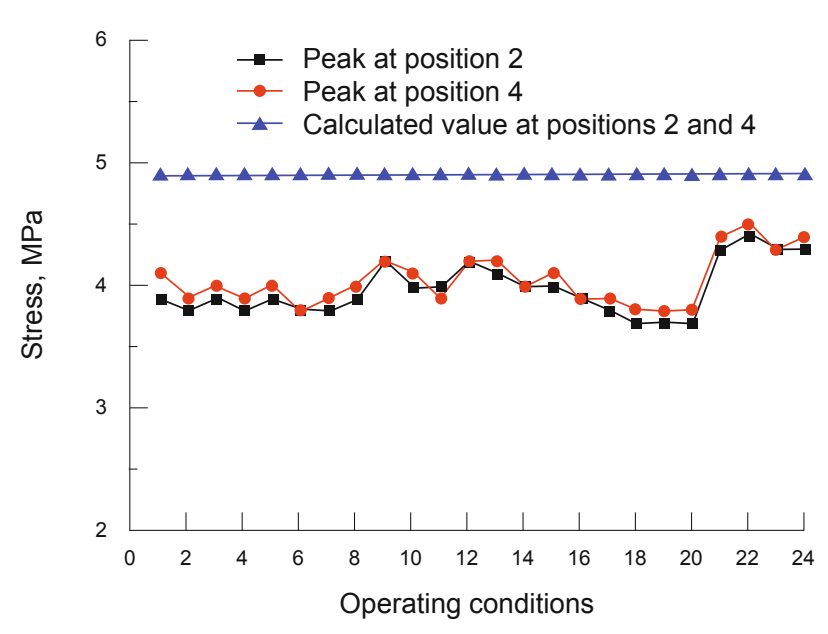

Fig.11 Measured and calculated values at positions 2 and 4 


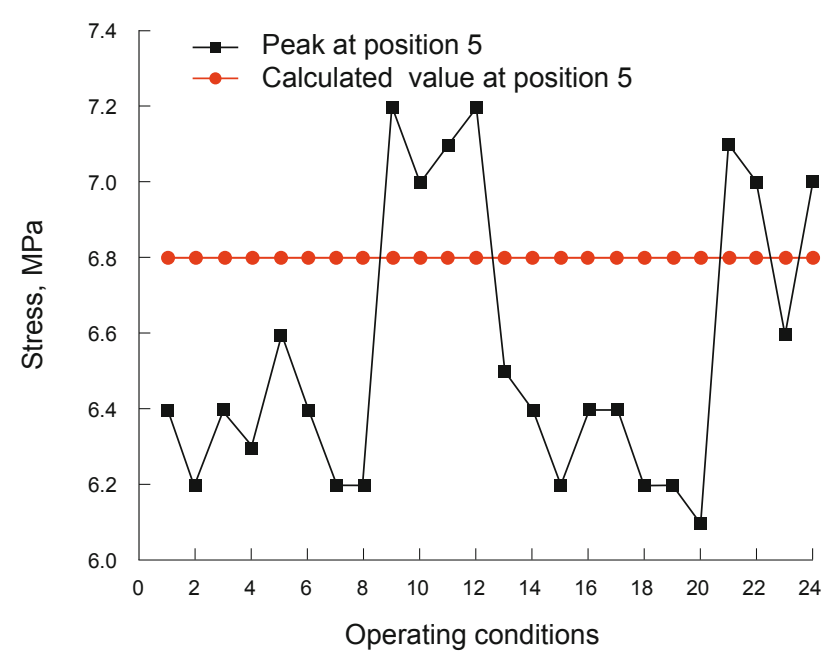

Fig.12 Measured and calculated values at position 5

\section{Conclusions}

The model test of the special lifting system for deepwater riser installation is one of the most important parts in deepwater riser installation technologies. The active truncated test developed in this paper for the model testing has proved to be an effective means for solving the difficulties in modeling so long and thin walled risers in deepwater. By applying the theory of similarity, the transferred control parameters are input to the 6-DOF Stewart platform and truncated position of the model riser in a model scale of 1:10 for the testing investigation. The method presented in this paper can accurately simulate lay barge movement and maintain the configuration of riser during the whole tests. The model test results provide very valuable information for application of the special lifting system for deepwater riser installation. And in this way, large tanker testing is avoided which is time-consuming and expensive.

\section{Acknowledgements}

The authors are grateful for the financial support from the National Natural Science Foundation of China (granted number 50979113), and the National 863 Program of China (granted number 2006AA09A105). Sincerely thanks go to the colleagues in the COOEC Ltd. (Offshore Oil Engineering Corporation Ltd.) and in the Offshore Oil/Gas Research Centre, China University of Petroleum, Beijing, who are involved in this wide range of research.

\section{References}

Bouwman J. Installation challenges with lifting and pull-in of the 20" SCR. Paper SPE 19061 presented at Offshore Technology Conference, 30 April-3 May 2007, Houston, Texas

Chen X, Zhang J, Johnson P, et al. Studies of the dynamics of truncated mooring line. The 10th ISOPE Conference, Seattle, USA, 2000. 94101

Duan M L. A lifting system for installation of deeperwater risers and subsea hardware. The 2010 SUT Technical Conference, Society for Underwater Technology, March 23-24, 2010, Rio de Janeiro, RJ, Brazil

Duan M L, Wang Y and Estefen S. Some recent advances in installation of deepwater risers. China Ocean Engineering. 2010. 24(4): in press (in Chinese)

Furutani K, Suzuki M and Kudoh R. Nanometre-cutting machine using a Stewart-platform parallel mechanism. Measurement Science and Technology. 2004. 15: 467-477

Greenberg J A and Park T J. The Ford driving simulator. SAE Technical Paper Series. 2004. (94): 176

Gusto B V. Vessel DP and motion analysis calculation report. Deepwater Pipelay Crane Vessel DPV7500C. 2006. 46-51

Jiang X Z, Li Z G, He N, et al. A new lifting system for installation of risers in deeper water. Proceedings of ISOPE-IDOT'2009, Beijing, China, June 28-July 1, 2009

Pytel A and Kiusalaas J. Engineering Mechanics: Statics and Dynamics. New York: Harper Collins College Publishers. 1994. 284-300

Watts S. Hybrid hydrodynamic modeling. Journal of Offshore Technology. 1999. 7(1): 13-14, 16-17

Watts S. Simulation of metocean dynamics: Extension of the hybrid modeling technique to include additional environmental factors. The SUT Workshop: Deepwater and Open Oceans, the Design Basis for Floaters, Houston, TX, USA, 2000

Yang J M, Xiao L F and Sheng Z B. Hydrodynamic experiment investigation of ocean engineering. Shanghai: Shanghai Jiao Tong University Press. 2008. 1

Yang S X, Yang T and Xun Y T. The development of the digital six-DOF stewart platform. Hydraulics \& Pneumatics. 2003. (8): 46-47 (in Chinese)

Zhang H M, Sun Z L, Yang J M, et al. Investigations into optimization design of equivalent water depth truncation. Science in China. 2009. 39 (4): 523-536 (in Chinese)

Zhang Z and Liu S J. Research into a simulation experimental scheme of heave compensation in deep sea mining. Modern Manufacturing Engineering. 2009. (1): 116-120 (in Chinese)

Zhen J W. CNOOC 201 begins to be built in the Rongsheng Heavy Industries Group Co. Ltd. Nantong Daily. September 17, 2008 (in Chinese)

Л.И.СеДОВ. Similitude Methodology and Theory of Dimension in Mechanics. Beijing: Science Press. 1982. 45-72 (in Chinese)

(Edited by Sun Yanhua) 